$£ 300$ to R.J. Tomkins to study dark-rumped petrels in the Galapagos;

$£ 250$ to Dr James O. Juvik for the first study of the endemic birds of Savai'i, Western Samoa;

$£ 200$ to Dr James Perran Ross, to help draw up conservation measures for the leatherback turtle in the Dominican Republic;

$£ 100$ to the British Trust for Conservation Volunteers, to maintain Britain's only raft spider population at Redgrave and Lopham Fens, Suffolk;

$£ 50$ to J.R. Hayward of Oxford for a study of Rothschild's starling in Bali.

\title{
Extinction or Rescue for the Hawksbill?
}

\section{Archie Carr and Anne Barkau Meylan}

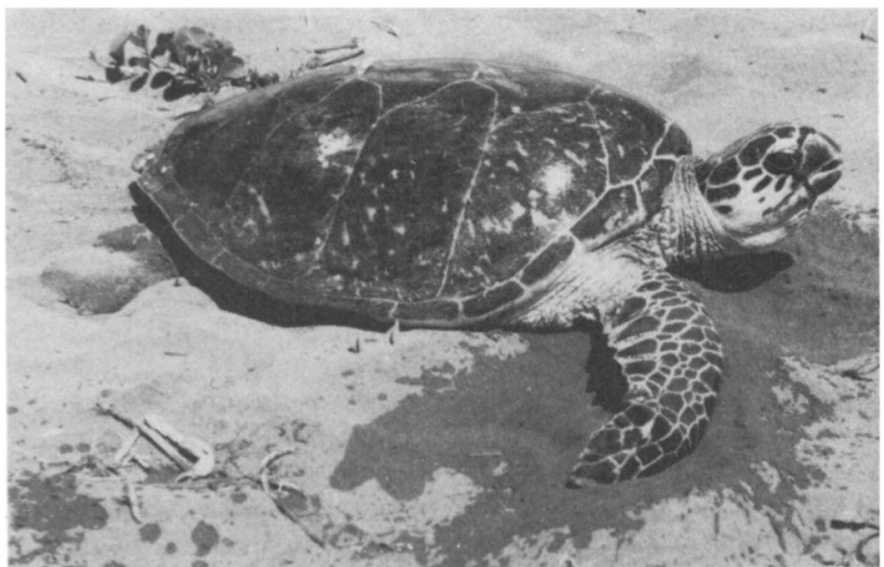

On the nesting beach

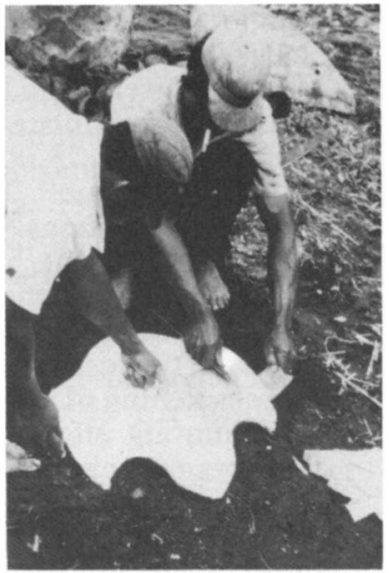

Removing the shell

The hawksbill turtle is seriously threatened with extinction, due mainly to trade in tortoiseshell. This has sent the price rocketing. Divers hunting for lobsters and snappers find it rewarding to search even the remotest reefs in the hope of getting the odd turtle - worth $\$ 200$ or more. The authors urge that only by stopping the trade through CITES can the hawksbill be saved.*

The survival outlook of the hawksbill turtle Eretmochelys imbricata has deteriorated seriously. The single most important reason is the burgeoning world-wide trade in tortoiseshell. In 1978, worldwide exports of all shell totalled $402,259 \mathrm{~kg} .{ }^{2}$ In 1979 , Japan alone imported $63,555 \mathrm{~kg}$, an increase of $20,000 \mathrm{~kg}$ over its 1978 level. ${ }^{1}$ There was a brief recession in the 1950 s due to plastic imitations, but then prices for real shell rose steadily and lately have skyrocketed. At US\$110-\$130 per kilogram in the Caribbean; the shell from a

*All marine turtle are on CITES Appendix I (which bans all trade), but Japan, which only joined CITES in 1980, and France have made reservations to exclude hawksbill turtles. 


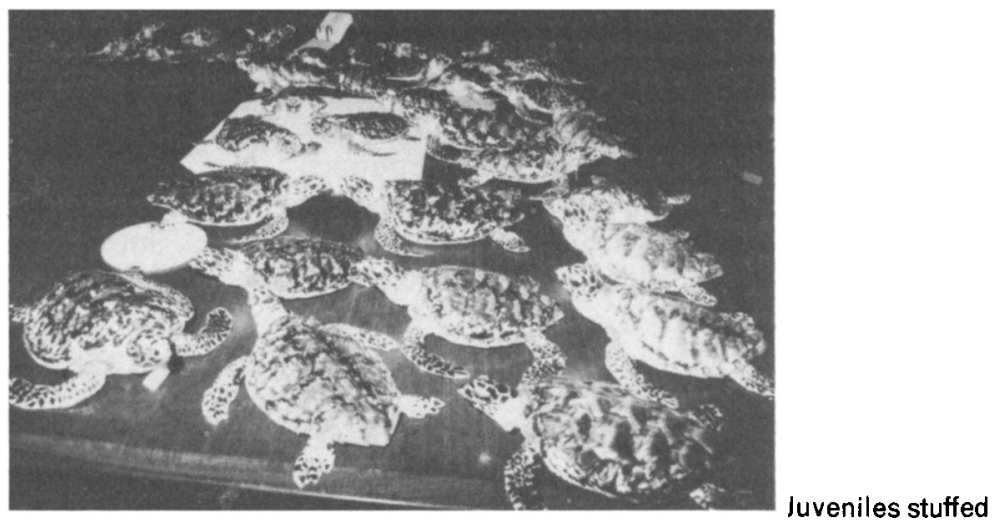

single hawksbill may bring a fisherman $\$ 200$ or more. Even very small hawksbills are increasingly vulnerable. Throughout the tropics, there is an active souvenir trade in stuffed juvenile turtles and polished carapaces. Worldwide estimates of the extent of this trade are difficult to obtain, but approximately 75,000 turtles per year are killed for this purpose in the Philippines alone. ${ }^{3}$

This international traffic is decimating the species, both on its nesting shores and in its foraging habitat on coral reefs. This has long been recognised by conservationists - the species was designated as endangered ten years ago - but only recently has it become evident that in some regions hunting will continue until the turtles have been completely extirpated. In the West Atlantic system, the slackening of pressure that is to be expected when a species becomes rare, and hunting effort exorbitant, is not occurring. The reason is that spiny lobsters and snappers occupy the same reef habitats in which hawksbills occur, and the prices that they bring are also inflated. All three are nowadays taken mainly by divers, who, despite the growing scarcity of turtles, are lured to the most remote hunting grounds by the sure reward of lobsters and snappers. The lobster divers systematically search every scrap of reef and the odd hawksbill that they take is extra profit. As a result, the West Atlantic reef country is being ransacked. With prices for shell what they are, there seems no possibility that local controls can be enforced. The extremely diffuse nesting of the species further complicates the problem, because sanctuaries will do little to stem the decline.

The only hope for the hawksbill, therefore, is CITES, and effective international regulation and enforcement.

\section{References}

1. JAPAN TARIFF ASSOCIATION 1979. Japan Exports and Imports.

2. MACK, D., N. DUPLAIX and S. WELLS In press. Sea turtles: animals of divisible parts. International trade in sea turtle products, 2nd edition. Proc. World Conference on Sea Turtle Conservation, 26-30 November 1979. Washington, D.C.

3. NEGERI, P.P., and SIOW KUAN TOW 1977. Observations on the exploitation of turtles in the Philippines. IUCN Marine Turtle Newsletter 3:7.

Department of Zoology, University of Florida, Gainesville, Florida 32611. 